\title{
In Vitro Optimization of Main Elements of the Grapes Reproduction Process
}

\author{
A A Batukaev1, D O Palaeva1, M S Batukaev², and E A Sobralieva1 \\ ${ }^{1}$ Chechen State University, Grozny, Russia \\ ${ }^{2}$ Chechen Research Institute of Agriculture, Grozny, Russia
}

\section{Abstract}

New methods for adapting in-vitro grape plants to in vivo conditions were developed. The use of growth regulators (6-BAP, 2iP, kinetin) enhanced rhizogenesis and increased the in-vitro plant reproduction coefficient. Lignohumate had a positive effect on plants and increased the leaf area and plant height 30 days after adaptation (concentration of $1.0 \mathrm{~g} / \mathrm{l})$. The use of the developed elements of clonal micro-reproduction and adaptation made it possible to significantly increase the reproduction factor, improve the quality of planting material, reduce costs of plants and increase profitability.

Keywords: Adaptation, in vitro, in vivo, test-tube plants, growth regulators, vessel-

Corresponding Author:

A A Batukaev

batukaevmalik@mail.ru

Received: 25 October 2019

Accepted: 15 November 2019

Published: 25 November 2019

Publishing services provided by Knowledge E

(c) A A Batukaev et al. This article is distributed under the terms of the Creative Commons Attribution License, which permits unrestricted use and redistribution provided that the original author and source are credited.

Selection and Peer-review under the responsibility of the AgroSMART 2019 Conference Committee.

\section{G OPEN ACCESS}

\section{Introduction}

Grapes is one of the most popular crops, both in the processing industry and consumption. However, there is no enough planting material of grapes. In the last decade, very few promising domestic varieties were included in the State Register of Reproduction Achievements of the Russian Federation. There are few new varieties due to difficult reproduction of grapes. Therefore, clonal micropropagation is the only effective way to obtain a root material of this plant. However, despite advances in the in vitro development, some valuable varieties have a low reproduction rate and poor viability for adaptation. Reliability of a reproduction factor is a crucial task.

The regeneration potential depends on hereditary characteristics and the phytosanitary and physiological state of the original plants. Preliminary preparation of mother plants for vegetative reproduction is very promising, especially for clonal micropropagation of grapes. According to most of the researchers, one of the most laborious and vulnerable stages of clonal micropropagation is adaptation of regenerants to non-sterile conditions: the share of dead in-vitro plants can reach 50\% or more. Poor development of the aerial parts and roots makes it impossible to grow quality planting material in a short 
time. This refers to difficult-reproduce and slow-growing varieties. High sensitivity of microplants to stress and large attacks on adaptation make it necessary to look for ways to increase their survival rate under stressful conditions and activate growth processes at the early stages of rearing. Earlier the laboratory of viticulture used biologically active substances for treating green cuttings of garden plants at the root formation stage. We hypothesized that the use of growth regulators with cytokinin activity, as well as humic substances, environmentally safe mycorrhizal and adaptogenic drugs, may facilitate transition of regenerants to independent mineral nutrition and photosynthesis under aseptic conditions, reduce losses of grapes and accelerate their growth after in vivo transplantation.

The object of research is new varieties of grapes included in the State Register. Optimization of the conditions and methods of in-vitro cultivation will accelerate development of varietal technologies of accelerated reproduction and introduce new varieties into production.

The research purpose is to optimize the technology of clonal micropropagation and methods for adapting new grape varieties to non-sterile conditions.

The tasks of the research are to obtain a healthy planting material, introduce a planting material certification system used in European countries, and improve the invitro technology of plant adaptation to in vivo conditions.

The use of the developed elements of clonal micropropagation of grape varieties increased the yield of high-quality planting material, reduced the cost of plants and increased profitability. Plants grown using biotechnological methods were used as mother plants.

\section{Materials and Methods}

The purpose of the work is to optimize the technology of clonal micropropagation and methods for adapting new grape varieties to non-sterile conditions.

Intensively growing green shoots of grapes were used. The plant explant was sterilized in a $2 \%$ sodium hypochlorite solution before isolation. Sterilized organs were placed in a sterile Petri dish. Before isolation, the outer chests were removed from the apex of the ocellus, successively exposing the apical meristem with primordial leaves. This operation was performed using a dissecting needle under a MBS-10 stereo-scopic microscope installed in a dustproof chamber (a laminar box). The meristems (200--600 microns) were isolated with a special preparation needle and immediately placed on the surface of the agar medium in Petri dishes, which were placed in the culture room 
with appropriate conditions: illumination of $3 . . .4$ thousand lux, temperature of $27 . . .28$ ${ }^{\circ} \mathrm{C}$, relative air humidity of $65 . . .70 \%$. The modified MS (Muraseige and Skoog) nutrient medium with vitamins was used: tiamin $1 \mathrm{mg} / \mathrm{l}$, pyridoxine $1 \mathrm{mg} / \mathrm{l}$, nicotinic acid $1 \mathrm{mg} / \mathrm{l}$, meso-inositum $50 \mathrm{mg} / \mathrm{l}$, cytokinin BAP (benzyl-aminopurine) -- $2 \mathrm{mg} / \mathrm{l}$, carbon source (sucrose) -- 2 \%, agar -- $0.7 \%$, and pH -- 6.4..6.5.

Intensively growing green shoots of grapes were cut into single-eye cuttings and meristems were isolated in laminar boxes. The following varieties were used for the experiment purposes: Rkatsiteli, Platov Jubilee, Flamingo, Nadezhda Azos, Avgustin.

6-benzylaminopurine (6-BAP), 2-isopentyl-adenine (2iP), kinetin and lignohumate were used as growth regulators.

Cultivation of plant material was carried out in Petri dishes and in test tubes of 40 x $120 \mathrm{~mm}$ in size, containing $20 \mathrm{ml}$ of nutrient medium. Explant transplantation was performed taking into account the following indicators: survival of the apical meristem and single-eye transplants, growth rate of the explants, development of the root system.

\section{Results and Discussion}

\subsection{Plant regeneration from the apical meristem}

The studies showed that at the first stage of cultivation, the meristems developed into a cluster of shoots of $2 \ldots 2.5 \mathrm{~mm}$ in size. These cluster shoots were re-transplanted onto the nutrient medium. Transplantation was carried out in biological tubes. These plants were cut and clones were obtained.

The meristems were isolated from the intensively growing green shoots using the above method. In late May, Nadezhda Azos, Platov's Anniversary, and Flamingo were sterilized. Apical shoots (2--4 eyes) were isolated and planted in the nutrient medium. Rkatsiteli was taken from the collection of the experimental plot. The highest share of infected meristems was observed for Platov's Anniversary and Nadezhda Azos (Table 1). A high share of survived apical meristems was observed for Rkatsiteli and Flamingo.

The survived apical meristems developed into a cluster of shoots of $2 . . .3 \mathrm{~mm}$ in size which were transplanted to the nutrient medium with changes in some components in the nutrient medium. Transplantation was carried out in biological tubes $40 \times 120 \mathrm{~mm}$ in size.

At the stage of cluster shoot transplantation, the survival rate is quite high with the exception of Nadezhda Azos (Table 2) with a high share of infected shoots. Within $40 . . .50$ days, regenerants of $6 . .10 \mathrm{~cm}$ in size developed. The next stage was microclonal 
TABLE 1: Survival of the apical meristem at the stage of introduction into the in vitro culture.

Variety
Rkatsiteli
Paltov's
anniversary
Flamingo
Nadezhda Azos

\begin{tabular}{c}
$\begin{array}{c}\text { Number of } \\
\text { planted } \\
\text { meristem }\end{array}$ \\
\hline 20 \\
\hline 20 \\
\hline 20 \\
\hline 20
\end{tabular}

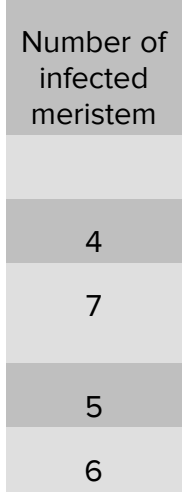

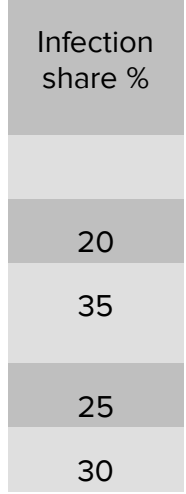

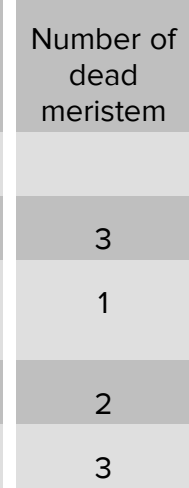

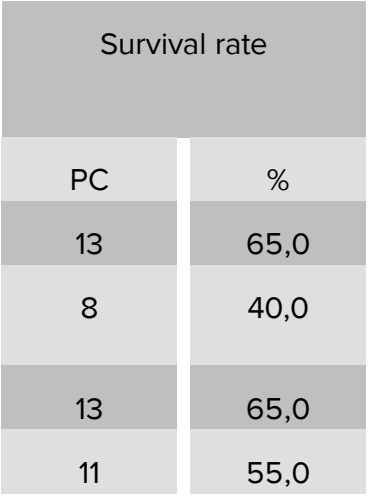

propagation. Regenerating plants were cut into fragments that included a node with a leaf and a bud (the lower part of the internode is $1 . .2 \mathrm{~cm}$ longer than the upper one). The microcurrents were incubated in biological tubes of $40 \times 120 \mathrm{~mm}$ in size in the agar medium so that the lower part of the internode was immersed in the agar. The tubes were covered with foil and placed in the culture room with appropriate conditions.

Summarizing the results, it should be noted that even a low survival rate for apical meristems makes it possible to cultivate and reproduce them to produce healthy plants.

TABLE 2: The survival of cluster shoots and formation of plant regenerants.

Variety
Rkatsiteli
Platov's anniversary
Platova
Flamingo
Nadezhda Azos

\begin{tabular}{|c|}
$\begin{array}{c}\text { Number of } \\
\text { cluster } \\
\text { shoots }\end{array}$ \\
\hline 13 \\
\hline 8 \\
13 \\
11
\end{tabular}

\begin{tabular}{c} 
Number of \\
infected ants \\
\hline 2 \\
\hline 0 \\
\hline 2 \\
\hline 3
\end{tabular}

\begin{tabular}{l} 
Number of \\
dead pkants \\
\hline 2 \\
1 \\
\hline 3 \\
3
\end{tabular}

\begin{tabular}{|c|c|}
\hline \multicolumn{2}{|l|}{ Survival rate } \\
\hline PC & $\%$ \\
\hline 9 & 69,2 \\
\hline 7 & 87,5 \\
\hline 8 & 61,5 \\
\hline 5 & 45,4 \\
\hline
\end{tabular}

\subsection{Use of growth regulators in vitro}

According to [1--3, 7, 8], the efficiency of clonal micropropagation of grapes depends on varietal characteristics. Most researchers used the Murashige-Skoog medium [1, 4--6] or its modifications, and BAP at the concentration of $0.5 . . .3 .0 \mathrm{mg} / \mathrm{I}[1,7,9]$ as a growth regulator.

In order to increase the reproduction factor, two variants of growth regulators were studied -- BAP combined with 2iP and BAP combined with kinetin. The modified Murasige-Skoog medium supplemented with BAP at the concentration of $0.5 \mathrm{mg} / \mathrm{l}$ and 
$1.0 \mathrm{mg} / \mathrm{l}$ was used for control. Single-eyed microcurrents of Augustine and Nadezhda Azos were planted in the experimental media. The duration of cultivation was 4 weeks. Then the reproduction factor and the average length of the shoots were determined (Tables 3, 4).

Table 3 shows that the presence of $2 \mathrm{iP}$ in the nutrient medium had a negative effect on development of additional shoots in grape explants, reducing both the reproduction factor and the average length of the shoots. For example, with the same BAP concentration of $0.5 \mathrm{mg} / \mathrm{l}$, the reproduction factor of Augustine decreased from 2.5 to 1.9; of Nadezhda Azos -- from 2.7 to 1.9. A further decrease in the reproduction factor was observed in the variants when using a combination of 6-BAP and 2iP at a concentration of $1.0 \mathrm{mg} / \mathrm{l}$.

TABLE 3: The effect of 6-BAP and 2iP on the reproduction factor and the average length of the shoots.

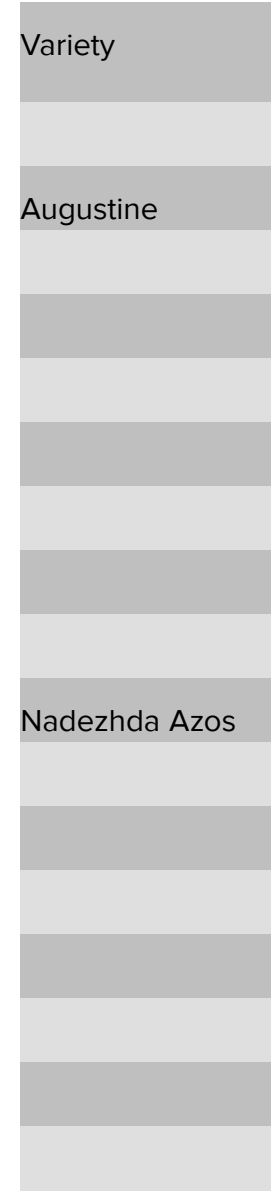

\begin{tabular}{c} 
Growth reg \\
6-BAP \\
\hline 0,5 \\
\hline 0,5 \\
\hline 0,5 \\
\hline 0,5 \\
1,0 \\
1,0 \\
1,0 \\
1,0 \\
\hline 0,5 \\
\hline 0,5 \\
0,5 \\
0,5 \\
1,0 \\
1,0 \\
1,0 \\
\hline 1,0 \\
\hline 1,0
\end{tabular}

\begin{tabular}{c} 
gulators, $\mathrm{mg} / \mathrm{l}$ \\
\hline-- \\
\hline 0,5 \\
1,0 \\
\hline 5,0 \\
\hline- \\
\hline 0,5 \\
1,0 \\
\hline 5,0 \\
-- \\
\hline 0,5 \\
1,0 \\
5,0 \\
\hline-- \\
\hline 0,5 \\
\hline 1,0 \\
\hline, 0 \\
\hline
\end{tabular}

$\begin{gathered}\text { Reproduction } \\ \text { coefficient }\end{gathered}$
$2,5 \pm 0,4$
$2,9 \pm 0,5$
$2,3 \pm 0,3$
$1,9 \pm 0,1$
$7,1 \pm 0,75$
$4,3 \pm 0,5$
$4,7 \pm 0,5$
$2,6 \pm 0,3$
$2,7 \pm 0,25$
$1,7 \pm 0,2$
$1,8 \pm 0,2$
$1,9 \pm 0,2$
$9,0 \pm 0,85$
$4,1 \pm 0,4$
$4,5 \pm 0,5$
$1,8 \pm 0,2$

\begin{tabular}{c}
$\begin{array}{c}\text { Average length of } \\
\text { shoots, } \mathrm{mm}\end{array}$ \\
\hline $37,7 \pm 3,2$ \\
$31,7 \pm 2,95$ \\
\hline $33,3 \pm 2,9$ \\
\hline $30,5 \pm 2,0$ \\
\hline $26,3 \pm 3,8$ \\
\hline $20,7 \pm 1,8$ \\
\hline $19,5 \pm 1,5$ \\
\hline $17,0 \pm 1,3$ \\
\hline $27,7 \pm 2,55$ \\
\hline $25,3 \pm 2,2$ \\
\hline $24,1 \pm 2,6$ \\
\hline $21,5 \pm 2,0$ \\
\hline $19,0 \pm 1,8$ \\
\hline $27,9 \pm 3,5$ \\
\hline $25,4 \pm 2,9$ \\
\hline $29,4 \pm 3,15$
\end{tabular}

In the BAP medium, in the control variants, the reproduction factor was more than twice as high as in the experimental variants.

The presence of kinetin combined with BAP in the nutrient medium had a positive effect on the development of explants. At the BAP concentration of $0.5 \mathrm{mg} / \mathrm{l}$, the 
presence of kinetin $(0.5 \mathrm{mg} / \mathrm{l})$ provided the maximum reproduction coefficient for both grape varieties (2.9) and slightly decreased the average length of the shoots. At the BAP concentration of $1.0 \mathrm{mg} / \mathrm{l}$, the presence of kinetin did not reduce the reproduction factor for Augustine as compared with the variant without kinetin. When cultivating Nadezhda Azos explants, a slight decrease in the reproduction factor was observed -- by $11 \%$ (kinetin $0.25 \mathrm{mg} / \mathrm{l}$ ) and $20 \%$ (kinetin $0.5 \mathrm{mg} / \mathrm{l}$ ). Thus, at the micropropagation stage, it is advisable to use BAP and kinetin at concentrations of $0.5 \mathrm{mg} / \mathrm{l}$ which provides the maximum reproduction factor.

TABLE 4: The effect of BAP combined with kinetin on the reproduction factor and the average length of the shoots of different grape varieties.

\begin{tabular}{|c|c|c|c|c|}
\hline \multirow[t]{2}{*}{ Variety } & \multicolumn{2}{|c|}{ Growth regulators, mg/l } & \multirow{2}{*}{$\begin{array}{l}\text { Reproduction } \\
\text { coefficient }\end{array}$} & \multirow{2}{*}{$\begin{array}{l}\text { Average length of } \\
\text { shoots, } \mathrm{mm}\end{array}$} \\
\hline & 6-BAP & $2 \mathrm{iP}$ & & \\
\hline \multirow[t]{8}{*}{ Augustine } & 0,5 & -- & $2,5 \pm 0,4$ & $37,7 \pm 3,2$ \\
\hline & 0,5 & 0,25 & $2,4 \pm 0,4$ & $38,0 \pm 3,0$ \\
\hline & 0,5 & 0,5 & $2,9 \pm 0,4$ & $33,3 \pm 3,3$ \\
\hline & 1,0 & -- & $7,1 \pm 0,75$ & $26,3 \pm 3,8$ \\
\hline & 1,0 & 0,25 & $7,4 \pm 0,8$ & $21,2 \pm 2,5$ \\
\hline & 1,0 & 0,5 & $7,5 \pm 0,7$ & $21,6 \pm 2,5$ \\
\hline & 0,5 & -- & $2,7 \pm 0,25$ & $27,7 \pm 2,55$ \\
\hline & 0,5 & 0,25 & $2,6 \pm 0,25$ & $34,5 \pm 3,1$ \\
\hline \multirow[t]{8}{*}{ Nadezhda Azos } & 0,5 & 0,5 & $2,9 \pm 0,3$ & $20,7 \pm 1,9$ \\
\hline & 1,0 & - & $9,0 \pm 0,85$ & $19,0 \pm 1,8$ \\
\hline & 1,0 & 0,25 & $8,0 \pm 0,7$ & $18,7 \pm 1,4$ \\
\hline & 1,0 & 0,5 & $7,1 \pm 0,6$ & $18,0 \pm 1,3$ \\
\hline & 0,5 & -- & $2,5 \pm 0,4$ & $37,7 \pm 3,2$ \\
\hline & 0,5 & 0,25 & $2,4 \pm 0,4$ & $38,0 \pm 3,0$ \\
\hline & 0,5 & 0,5 & $2,9 \pm 0,4$ & $33,3 \pm 3,3$ \\
\hline & 1,0 & -- & $7,1 \pm 0,75$ & $26,3 \pm 3,8$ \\
\hline
\end{tabular}

\subsection{Adaptation of in-vitro grape plants in vivo conditions}

At the plant adaptation stage in ex-vitro conditions, the study of the effect of potassium lignohumate is associated with a number of its positive properties, including the ability to increase plant resistance to adverse environmental factors. The shoots were treated with an aqueous solution which was used for watering the substrate immediately after 
transplantation. To identify the optimal effect, different concentrations of the substance were studied. Water was used for control. The data obtained are presented in Table 5.

Table 5 shows that lignohumate had a positive effect on plants, especially on their leaves and height (at the concentration of $1.0 \mathrm{~g} / \mathrm{l}$ ).

During adaptation to low air humidity, slight decay and drying of the edges of leaf blades were observed. This was characteristic of lower leaves which find it difficult to rebuild the transpiration system. When using lignohumate (especially at 1.0 and $2.0 \mathrm{~g} / \mathrm{l}$ ), the desiccation of leaf blades was observed less frequently. Plants adapted to lower air humidity better and were stronger and greener. All this increased their survival rate.

In general, the results of this experiment indicate a positive effect of lignohumate $(1.0--2.0 \mathrm{~g} / \mathrm{l})$ on increasing the viability of adaptable Augustine grape plants.

TABLE 5: The use of lignohumate for adapting grape plants to non-sterile conditions, Augustine.

\begin{tabular}{|c|c|c|c|c|}
\hline $\begin{array}{l}\text { Accounting time, } \\
\text { days after } \\
\text { beginning of the } \\
\text { experiment }\end{array}$ & Lignohumate, g/l & Plant height, $\mathrm{cm}$ & $\begin{array}{c}\text { The number of } \\
\text { leaves, }\end{array}$ & $\begin{array}{l}\text { Average leaf } \\
\text { area, } \mathrm{cm}^{2}\end{array}$ \\
\hline \multirow[t]{5}{*}{15} & Control & 5,0 & 3,8 & 4,0 \\
\hline & 0,5 & 4,8 & 3,7 & 4,3 \\
\hline & 1,0 & 4,8 & 3,9 & $4,5^{*}$ \\
\hline & 2,0 & 5,2 & 4,0 & $4,5^{*}$ \\
\hline & $\mathrm{HCP}_{0,95}$ & 0,5 & 0,4 & 0,4 \\
\hline \multirow[t]{5}{*}{30} & Control & 6,2 & 4,9 & 6,2 \\
\hline & 0,5 & 6,2 & 5,0 & $6,9^{*}$ \\
\hline & 1,0 & $7,0^{*}$ & 5,2 & 8,1 \\
\hline & 2,0 & 6,6 & 5,4 & $7,7^{*}$ \\
\hline & $\mathrm{HCP}_{0,95}$ & 0,5 & 0,6 & 0,5 \\
\hline \multirow[t]{5}{*}{50} & Control & 7,6 & 5,3 & 12,6 \\
\hline & 0,5 & 7,6 & 5,5 & $13,5^{*}$ \\
\hline & 1,0 & 8,2 & 5,6 & $14,9^{*}$ \\
\hline & 2,0 & 7,8 & 5,6 & $14,4^{*}$ \\
\hline & $\mathrm{HCP}_{0,95}$ & 0,9 & 0,4 & 0,8 \\
\hline
\end{tabular}

* Differences between experiment and control variants are significant with a probability of $>95 \%$. 


\section{Conclusion}

The research proved that it is possible to reproduce grape varieties by in-vitro isolation of tissues and organs due to the high potential of grapes for vegetative reproduction in general and for microclonal in particular.

The survival rate of the apical meristems $(10--12 \mathrm{~cm})$ makes it possible to cultivate and propagate them (by replanting) and obtain virus-free planting material.

6-BAP at the concentration of $0.5 \ldots 1.0 \mathrm{mg} / \mathrm{l}$ is the most efficient growth regulator. For mass reproduction of shoots (of one-eye explants), 6-BAP concentration of $2 \mathrm{mg} / \mathrm{l}$ was optimal.

The presence of kinetin in combination with 6-BAP in the nutrient medium had a positive effect on explants. Thus, at the 6-BAP concentration of $0.5 \mathrm{mg} / \mathrm{l}$, the presence of kinetin $(0.5 \mathrm{mg} / \mathrm{l})$ provided the maximum reproduction factor for the tested grape varieties. To improve the adaptation of invitro plants of the vineyard to non-sterile conditions, as well as to increase survival and improve the quality of plants, it is necessary to use potassium lignomate $(1.0 \mathrm{~g} / \mathrm{l})$.

\section{Acknowledgment}

The research was financially supported by the Ministry of Science and Education of the Russian Federation as part of the Federal Target Program "Research and development in priority areas of development of the scientific and technological complex of Russia for 2014--2020". (Agreement No. 14.577.21.0292 of 04.12.2018) with a unique project identifier RFMEFI57718X0292

\section{References}

[1] Batukayev, A.A. (1998). Improvement of the technology of accelerated reproduction and improvement of the planting material of grapes by the in-vitro method. Moscow: MSHA, 222 p.

[2] Beloshapkipa, O.O., Zharkova, I.V. (2001). The use of biological preparations for the clonal micropropagation of strawberries. (Report of TSHA, no. 273, part 2, pp. 284-289).

[3] Vysotskiy, V.A. (2011). Biotechnological techniques in modern gardening. Collection of scientific works of the All-Union Academy of Agricultural Sciences, vol. XXVI, pp. 3--10. 
[4] Kornatskiy, S.A. (2001). The most significant elements of the industrial technology of clonal micropropagation of tree cultures. Industrial production of a healthy planting material of fruit crops. Moscow, pp. 103--104.

[5] Matushkina, O.V., Pronina, I.N. (2016). Regenerative ability of promising apple varieties in vitro, Fruit and berry growing in Russia. Coll. of scientific works, VSTISP, vol. XXXXVII, pp. 211--215.

[6] Tsatsenko, N.N., Bratkova, L.G., Malykhina, A.N., Mashchenko, M.N. (2017). Cultivation of grapes merislonus in non-sterile conditions. Fruit growing and viticulture of the South of Russia, no. 43(1), pp. 30--41.

[7] Griffis, J.L., Hennen, G., Oglesby, R.P. (1984). Establishing tissue-cultured plants in soil. Comb. Proc. Intern. Plant Propagators Soc., vol. 33, pp. 618--622.

[8] Filiti N. et al. (1987). In vitro rhizogenesis: histoanatomicul aspects on Prunus root stock. Advans in Horticultural Sci., vol. I, no. 1, pp. 34--38.

[9] Preece, J.E. (2002). The most tricky part of micropropagation: establishing plants in greenhouses and fields. Comb. Proc. Intern. Plant Propagators' Soc., vol. 51, pp. 300--303.

[10] Batukaev, A.A. (2018). Use of growth regulators in grapes grinding by in vitro method". 18th International Multidisciplinary Scientific GeoConference, SGEM-2018. vol. 18, iss. 6.2, pp. 783--789, 30 June -- 9 July, Albena, Bulgaria. 